\title{
ANALISA PENYEBAB TINGGINYA SUHU GAS BUANG DUAL FUEL DIESEL ENGINE DENGAN METODE FAULT TREE ANALYSIS
}

\author{
Nono Sukirno ${ }^{a}$, Dwi Prasetyo ${ }^{b}$ dan Moh. Aziz Rohman ${ }^{c}$ \\ ${ }^{a}$ Taruna (NIT.48114239.T) Program Studi Teknika PIP Semarang \\ ${ }^{\mathrm{b}}$ Dosen Program Studi Teknika PIP Semarang \\ ${ }^{c}$ Dosen Program Studi Nautika PIP Semarang
}

\begin{abstract}
ABSTRAK
Dual Fuel Diesel Engine (Mesin Bahan Bakar Ganda) merupakan mesin dengan pemanfaatan dua bahan bakar dalam proses pembakarannya untuk memperoleh tenaga kerja pada mesin. Jenis bahan bakar yang digunakan meliputi bahan bakar Methane Gas $\left(\mathrm{CH}_{4}\right)$ dan MGO (Marine Gas Oil). Methane $\left(\mathrm{CH}_{4}\right)$ dihasilkan dari Vapour Cargo Tank LNG (Liquified Natural Gas). Tujuan dari penelitian ini adalah untuk mengetahui apa saja penyebab tingginya suhu gas buang terhadap kinerja Dual Fuel Diesel Engine di MV. Tangguh Palung dengan menggunakan metode analisis data Fault Tree Analysis. Dari analisis data penelitian di hasilkan beberapa rumusan masalah yaitu, faktor-faktor yang dapat menyebabkan tingginya suhu gas buang pada Dual Fuel Diesel Engine adalah kurangnya suplai udara pembakaran dalam ruang pembakaran mesin, komposisi pembakaran yang tidak sesuai antara bahan bakar minyak dan gas, serta suhu Engine Room yang terlalu panas. Dampak yang di timbulkan adalah kerusakan pada komponen-komponen permesinan dan penurunan kinerja dari Dual Fuel Diesel Engine. Untuk mengatasi penurunan kerja pada Dual Fuel Diesel Engine adalah dengan melaksanakan perawatan dan perbaikan pada setiap komponen permesinan yang mengalami masalah dan kerusakan sesuai dengan Running Hours dan Instruction Manual Book.
\end{abstract}

Kata kunci: dual fuel diesel engine, fault tree analysis, gas buang

\section{PENDAHULUAN}

A. Latar belakang

Dual Fuel Diesel Engine (Mesin Bahan Bakar Ganda) merupakan salah satu mesin teknologi baru dengan pemanfaatan dua bahan bakar dalam proses pembakarannya untuk memperoleh tenaga kerja pada mesin. Jenis bahan bakar yang digunakan meliputi bahan bakar Gas dan MGO (Marine Gas Oil).

Jenis bahan Bahan Bakar Gas yang digunakan adalah Methane $\left(\mathrm{CH}_{4}\right)$ yang kandungan utamanya terdiri dari hidrokarbon, Methane $\left(\mathrm{CH}_{4}\right)$ dihasilkan dari Vapour Cargo Tank LNG (Liquified Natural Gas). Dikarenakan kapal LNG/C Tangguh Palung sebagai tempat penulis melaksanakan penelitian dan praktik laut merupakan kapal gas yang berjenis Semi Pressurise. Untuk perawatan pada cargo LNG dengan menjaga tekanan tetap di kisaran $14 \mathrm{kPa}$, jika melebihi dari tekanan tersebut vapor LNG harus dibakar atau digunakan sebagai bahan bakar Dual Fuel Diesel Engine.

Bahan bakar utamanya adalah gas yang dikompresikan bersama udara dengan penyalaan menggunakan bahan bakar MGO sebagai pematik awal. Vapour (uap gas) yang dihasilkan dihisap dan dialirkan oleh Compressor yang disebut Low Duty Compressor (kompresor tekanan rendah) ke mesin diesel di kamar mesin. 
Gangguan pemakaian gas methane menjadi bahan bakar pada dual fuel diesel engine ini adalah tingginya suhu gas buang yang melebihi batas normal sehingga mempengaruhi kinerja dari DFDE (Dual Fuel Diesel Engine).

Dengan dilatarbelakangi permasalahan tersebut, maka penulis mengambil judul "Analisa penyebab tingginya suhu gas buang terhadap kinerja Dual Fuel Diesel Engine di MV. Tangguh Palung dengan metode Fault Tree Analysis"

B. Rumusan masalah

Berdasarkan latar belakang yang telah diuraikan di atas dan untuk menyusun permasalahan, disusun berupa pertanyaan-pertanyaan, pembahasan yang memerlukan jawaban dan solusi pemecahannya adalah sebagai berikut:

1. Faktor-faktor yang mempengaruhi tingginya suhu gas buang pada Dual Fuel Diesel Engine?

2. Dampak yang diakibatan dari tingginya suhu gas buang pada Dual Fuel Diesel Engine?

3. Bagaimana cara mengatasi penurunan kinerja Dual Fuel Diesel Engine?

\section{LANDASAN TEORI}

\section{A. Tinjauan Pustaka}

Dalam penelitian ini penulis memilih metode penelitian fault tree analysis.

1. Metode faul tree analysis

a. Sejarah dan pengertian fault tree analysis

Fault tree analysis pada awalnya dikembangkan pada tahun 1962 di Bell Telephone Laboratories oleh HA Watson, di bawah kontrak Angkatan Udara Amerika Serikat divisi balistik sistem untuk mengevaluasi Minuetman I Intercontinental Rudal Balistik. Launch control system penggunaan pohon kesalahan sebagai alat analisis kegagalan oleh para ahli reliabilitas. Setelah penggunaan diterbitkan pertama FTA (fault tree analysis) pada tahun 1962 digunakan Minuteman I Launch Control keselamatan studi, Boeing company dan AVCO diperluas fault tree analysis system Minuteman II seluruh pada tahun 1963-1964. Fault tree analysis mendapatkan liputan luas pada 1965.

b. Prinsip kerja metode fault tree analysis

Metode FTA merupakan sebuah teknik analisis yang menggunakan prinsip pohon kesalahan dengan sederhana dijelaskan sebagai teknik analitis, dimana sebuah masalah ditentukan dan di analisi mulai dari penyebab terjadinya sebuah masalah sampai akar-akar dari permasalahan. Hingga sebuah masalah sampai pada titik puncak masalah (top event).

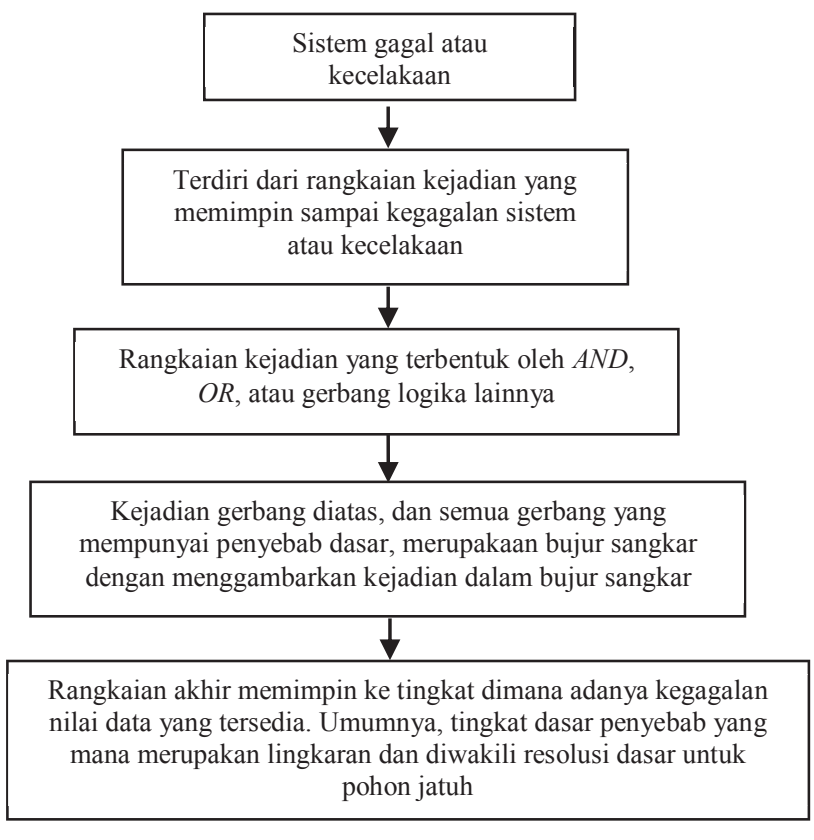

c. Simbol dan istilah dalam metode fault tree analysis

1) Simbol gerbang (gate symbol)

Simbol gerbang menggambarkan hubungan antara input dan output kegiatan. Simbul gerbang logika sebagai berikut: 
a) OR gate (gerbang $O R$ )

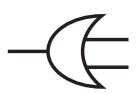

Gambar 1. Gerbang $O R$

Gerbang $O R \quad$ dipakai untuk menunjukkan bahwa kejadian yang akan muncul terjadi jika satu atau lebih kejadian gagal yang merupakan inputnya terjadi.

b) AND gate (gerbang AND)

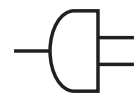

Gambar 2. Gerbang AND

Gerbang $A N D$ digunakan untuk menunjukkan kejadian output muncul hanya jika semua input terjadi.

c) Inhibit gate (gerbang inhibit)<smiles>CC1CCC(C)C(C)C1</smiles>

Gambar 3. Gerbang INHIBIT

Gerbang INHIBIT, dilambangkan dengan segi enam, merupakan kasus khusus dari gerbang $A N D$. Output disebabkan oleh satu input.

d) Exclusive OR gate (exclusive gerbang OR)

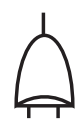

Gambar 4. EXCLUSIVE OR

Gerbang EXCLUSIVE OR adalah gerbang $O R$ dengan kasus tertentu, yaitu kejadian output muncul jika satu kejadian ikut muncul. e) Priority AND gate (prioritas gerbang AND)

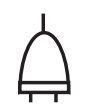

Gambar 5. PRIORITY AND

Gerbang PRIORITY AND adalah gerbang $A N D$ dengan syarat dimana kejadian output muncul hanya jika semua kejadian input muncul dengan urutan tertentu.

2) Simbol transfer

a) Triangle-in

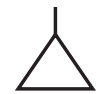

Gambar 6. Triangle-in

Triangle-in atau transfers-in, titik dimana sub-fault tree bisa dimulai sebagai kelanjutan pada transfers out

b) Triangle out

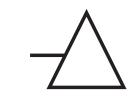

Gambar 7. Triangle-out

Triangle-out atau transfers out, titik dimana fault tree dipecah menjadi sub-fault tree.

3) Event symbol (simbol kejadian)

Simbol kejadian adalah simbol-simbol yang berisi keterangan kejadian pada sistem yang ada pada suatu proses terjadinya top event. Terdapat 5 macam simbol, yaitu: 
a) Basic event/primery event

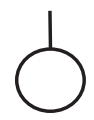

Gambar 8. Basic Event

Simbol lingkaran merupakan kegagalan atau kesalahan dalam komponen sistem kejadian yang tidak diharapkan yang dianggap sebagai penyebab dasar sehingga tidak perlu dilakukan analisa lebih lanjut. Simbol ini berdasarkan data yang cukup.

b) Undeveloped event

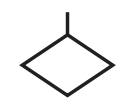

Gambar 9. Undeveloped event

Simbol belah ketupat (diamond) suatu kejadian yang tidak dapat lagi berkembang lebih lanjut karena tidak tersedianya informasi karena kejadiannya tidak berhubungan menjadi suatu kejadian akhir dari suatu masalah yang terjadi pada suatu penelitian.

c) Conditioning event

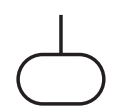

Gambar 10. Conditioning event

Simbol oval ini untuk menyatakan conditioning event, yaitu suatu kondisi atau batasan khusus yang diterapkan pada suatu gerbang (biasanya pada gerbang INHIBIT dan PRIORITY AND).

d) External event

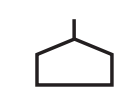

Gambar 11. External event

Simbol rumah digunakan untuk menyatakan external event yaitu kejadian yang diharapkan muncul secara normal dan tidak termasuk dalam kejadian gagal.

e) Intermediate event

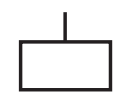

Gambar 12. Intermediate event

Simbol persegi panjang ini berisi kejadian yang muncul dari kombinasi kejadian-kejadian input gagal yang masuk ke gerbang.

\section{B. Dasar-dasar DFDE (Dual Fuel Diesel} Engine)

1. Pengertian dual fuel diesel engine

Menurut Instruction Manual Book of Wartsila Dual Fuel Diesel Engine 50DF Type, dual fuel diesel engine adalah mesin yang bekerja dengan gas alam sebagai bahan bakar utama dan minyak diesel sebagai cadangan bahan bakar. Mesin ini didesain menghasilkan tenaga listrik untuk menggerakkan mesin penggerak kapal seperti propulsion. Mesin ini dapat ditukarkan dari operasi gas ke operasi bahan bakar salinan cadangan pada beban kapanpun. Mesin dapat ditukarkan juga dari operasi bahan bakar salinan cadangan ke operasi gas saat beban $80 \%$ penuh. Mesin ini juga mampu bekerja pada HFO dan dapat dioperasikan sebagai mesin 
konvensional diesel ketika bekerja pada HFO.

\section{Kerangka pikir penelitian}

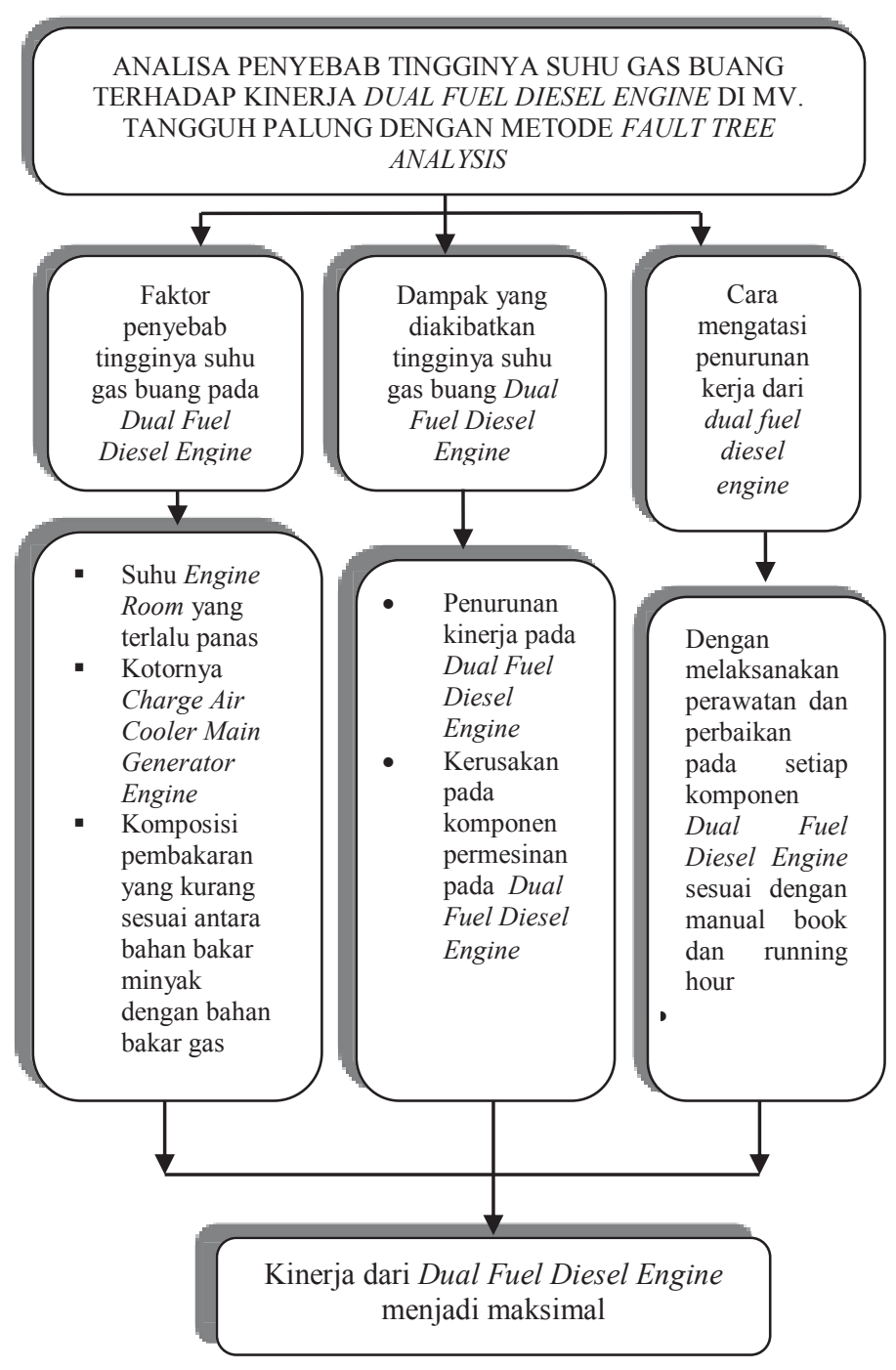

Gambar 13. Kerangka Pikir Penelitian

\section{METODE PENELITIAN}

A. Waktu dan tempat penelitian

1. Waktu penelitian

Tanggal 25 Agustus 2013 sampai 26 Agustus 2014.

2. Tempat penelitian

MV. Tangguh Palung LNG Carrier, "K" Line Ship Management

B. Data yang diperlukan

\section{Data Primer}

Data primer adalah data yang diperoleh dari responden melalui kuesioner, kelompok fokus, dan panel, atau juga data hasil wawancara peneliti dengan narasumber. Data yang diperoleh dari data primer ini harus diolah lagi. Sumber data yang langsung memberikan data kepada pengumpul data. (V. Wiratna Sujarweni 2014: 73)

2. Data Sekunder

Data sekunder adalah data yang didapat dari catatan, buku, majalah berupa laporan keuangan publikasi perusahaan, laporan pemerintah, artikel, buku-buku sebagai teori, majalah, dan lain sebagainya. Data yang diperoleh dari data sekunder ini tidak perlu diolah lagi. Sumber yang tidak langsung memberikan data pada pengumpul data. (V. Wiratna Sujarweni 2014: 74)

C. Metode pengumpulan data

1. Metode observasi (pengamatan)

Teknik pengumpulan data yang dilakukan melalui suatu pengamatan, disertai pencatatan-pencatatan terhadap keadaan atau perilaku obyek sasaran penelitian.

2. Metode studi pustaka

Metode studi pustaka dilakukan untuk menunjang metode wawancara dan observasi yang telah dilakukan.

3. Metode dokumentasi

Metode pengumpulan data kualitatif dengan melihat atau menganalisis dokumen-dokumen yang dibuat oleh subjek sendiri atau oleh orang lain oleh subjek.

D. Teknik analisis data

Beberapa tahapan Fault tree analisys, sebagai berikut:

1. Tentukan kejadian paling atas/utama (top event);

2. Tetapkan batasan fault tree analysis;

3. Periksa sistem berbagai elemen berhubungan dan kejadian paling atas (top event);

4. Buat pohon kesalahan; 
Nono Sukirno, Dwi Prasetyo dan Moh. Aziz Rohman

5. Analisis pohon kesalahan;

6. Persiapkan rencana tindakan perbaikan untuk mencegah kegagalan.

\section{HASIL PENELITIAN DAN PEMBAHASAN}

A. Gambaran umum obyek yang diteliti

Pada bab ini penulis akan menjelaskan pembahsan terhadap permasalahan yang terjadi pada obyek yang diteliti menggunakan metode fault tree analysis. Obyek yang diteliti adalah Dual Fuel Diesel Engine 12V50DF yang ada di MV. Tangguh Palung, dan spesifikasinya sebagai berikut:

Type : Dual Fuel Diesel Engine 12V50DF

Maker : WARSILA

Engine Output $: 11,400 \mathrm{KW}$

Engine Speed : 500/514 Rpm

Pengertian 12V50DF adalah mesin dengan 12 silinder yang berbentuk $\mathrm{V}$ terdapat 2 cabang masing-masing cabang memiliki 6 silinder yang kemiringannya $60^{\circ}, \quad$ mempunyai diameter silinder $50 \mathrm{~cm}$ serta sistem pembakaran dengan menggunakan bahan bakar ganda yaitu gas dan Marine Gas Oil.

B. Analisa hasil penelitian

1. Langkah-langkah membuat fault tree analysis:

a. Tujuan fault tree analysis mengetahui faktor-faktor penyebab tingginya suhu gas buang pada Dual Fuel Diesel Engine.

b. Definisikan top event penyebab tingginya suhu gas buang pada Dual Fuel Diesel Engine.

c. Definisikan batasan, cakupan dari sistem dan perhatikan aturan dari fault tree analysis.
1) Kegunaan dari sistem

Sistem ini dirancang agar dapat mencari faktor-faktor penyebab penurunan kinerja dari Dual Fuel Diesel Engine.

2) Batasan fisik

Sistem ini bekerja dengan baik jika semua komponenkomponen dari tiap-tiap bagian berfungsi dengan baik.

3) Batasan analitis

Batasan ini mencakup pada semua kemungkinan atau kontribusi yang bisa terjadi pada sistem.

4) Kondisi awal

Kondisi awal dari sistem ini adalah saat dimana semua komponen-komponen Dual Fuel Diesel Engine beroperasi.

d. Memulai membuat fault tree dari atas

Disini akan diselidiki kejadian apa saja yang bisa mengakibatkan top event terjadi.

e. Penggunaan aljabar boolean

Aljabar boolean merupakan aljabar yang berhubungan dengan variabel-variabel biner dan operasi-operasi logik. Operatoroperator logik dasar yang ada pada aljabar boolean adalah $A N D$, OR.

Operator $A N D$ atau "dan" atau perkalian boolean mempunyai simbol (.) dimana untuk $\mathrm{x} € \mathrm{~B}$ mempunyai nilai.

$1.1=1$ Rumus $4.1 \quad 0.1=0$ Rumus 4.3

$1.0=0$ Rumus $4.2 \quad 0.0=0$ Rumus 4.4

Operator $O R$ atau "atau" atau perkalian boolean mempunyai simbol $(+)$ dimana $x \in B$ mempunyai nilai.

$1+1=1$ Rumus $4.5 \quad 0+1=1$ Rumus 4.7

$1+0=1$ Rumus $4.6 \quad 0+0=0$ Rumus 4.8 
Macam-macam gerbang logika yang penulis pakai dalam penelitian ini hanya satu gerbang saja, yaitu gerbang $O R$.

Tabel 1. Tabel kebenaran gerbang $O R$

\begin{tabular}{|c|c|c|}
\hline \multicolumn{2}{|c|}{ INPUT } & OUTPUT \\
\hline $\mathrm{A}$ & $\mathrm{B}$ & OR \\
\hline 0 & 0 & 0 \\
\hline 0 & 1 & 1 \\
\hline 1 & 0 & 1 \\
\hline 1 & 1 & 1 \\
\hline
\end{tabular}

Tabel 2. Tabel kebenaran gerbang AND

\begin{tabular}{|c|c|c|}
\hline \multicolumn{2}{|c|}{ INPUT } & OUTPUT \\
\hline $\mathrm{A}$ & $\mathrm{B}$ & $A N D$ \\
\hline 0 & 0 & 0 \\
\hline 0 & 1 & 0 \\
\hline 1 & 0 & 0 \\
\hline 1 & 1 & 1 \\
\hline
\end{tabular}

C. Pembahasan masalah

1. Faktor-faktor yang mempengaruhi tingginya suhu gas buang pada Dual Fuel Diesel Engine.

Dalam permasalahan yang diambil penulis bahwa suhu gas buang yang terlalu tinggi mencapai suhu $540^{\circ} \mathrm{C}$ yang normalnya pada saat mesin sedang dalam kondisi Gas mode suhu gas buang memiliki rata-rata $330^{\circ} \mathrm{C}$.

Dalam penelitian ini didapati beberapa top event dari kejadian tingginya suhu gas buang terhadap kinerja dari Dual Fuel Diesel Engine, berikut adalah gambar diagram pohon kesalahan tingginya suhu gas buang terhadap kinerja dari Dual Fuel Diesel Engine.

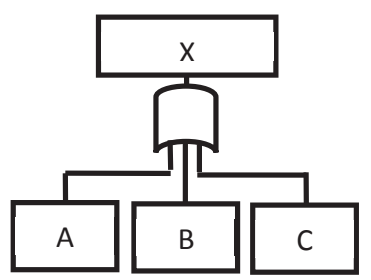

Bagan 1. Analisis tingginya penyebab tingginya suhu gas buang
Keterangan:

$\mathrm{X}$ : Tingginya suhu gas buang pada Dual Fuel Diesel Engine

A : Kurangnya suplai udara pembakaran dalam ruang silinder

B : Komposisi bahan bakar untuk pembakaran yang kurang sesuai

C : Suhu Engine Room terlalu panas

Analisa penyebab top event pertama adalah mengenai kurangnya suplai udara pembakaran dalam ruang silinder.

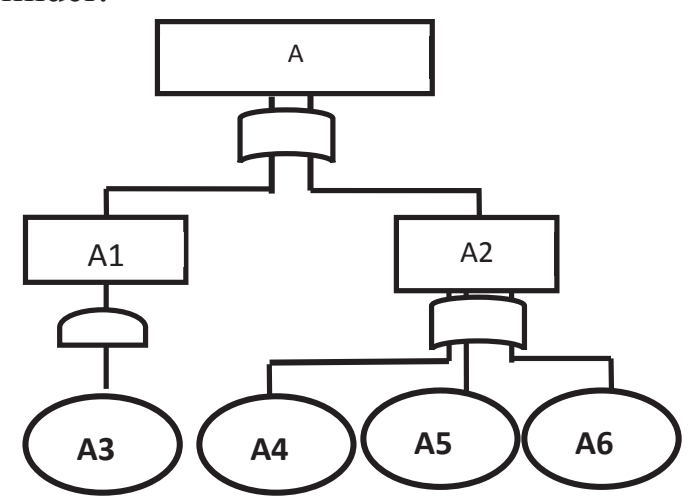

Bagan 2. Pohon kesalahan kurangnya suplai udara pembakaran dalam ruang silinder

Keterangan:

A : Kurangnya suplai udara pembakaran dalam ruang silinder

A1 : Kurangnya suplai udara dari blower suplai fan

A2 : Kurang maksimalnya kinerja dari Turbocharge

A3 : Rusaknya Elektro motor

A4 : Tidak sesuainya pembukaan Exhaust Gas Waste Gate Valve

A5 : Kotornya sudu-sudu turbine side pada Turbocharge

A6 : Bocornya exhaust gas below

Penjabaran pohon kesalahan dari top event pertama kurangnya suplai udara pembakaran kedalam ruang silinder. Dalam keadaan normal untuk lean burn combustion engine suplai udara ke dalam silinder 
mencapai lebih dari 15:1, serta air flow pada saat mesin kerja maksimal yaitu $17 \mathrm{Kg} / \mathrm{s}$, dikarenakan beberapa faktor sehingga suplai udara ke dalam silinder hanya mencapai $13 \mathrm{Kg} / \mathrm{s}$, maka dari keterangan tersebut dapat ditarik beberapa faktor penyebab yaitu sebagai berikut:

a. Kurangnya suplai udara dari Blower Supplay Fan (A1)

Kurangnya suplai udara dari Blower Supplay Fan sebagai intermediet event merupakan penghubung antara top event dan basic event, dari intermediet event kurangnya suplai udara dari Blower Supplay Fan (A1) akan dijabarkan lagi menjadi basic event rusaknya electro motor (A3).

Rusaknya Elektro Motor, dari intermediet event kurangnya suplai udara dari Blower Supplay Fan dapat ditarik menjadi basic event rusaknya elektro motor pada supplay fan berpengaruh terhadap kualitas pembakaran serta kinerja dari permesinan itu sendiri.

b. Kurang maksimalnya kerja dari turbocharge (A2)

1) Tidak sesuainya pembukaan Exhaust Gas Waste Gate Valve (A4)

Tidak sesuainya pembukaan pada Exhaust Gas Waste Gate Valve akan mengakibatkan terlalu banyaknya gas buang yang langsung by pass menuju ke cerobong sebelum melewati turbine side pada turbocharge, sehingga akan berakibat pada turunnya putaran dari turbocharge yang akhirnya putaran kompressor pada turbocharge juga akan berkurang.

2) Kotornya sudu-sudu turbine pada turbocharge (A5)
Kebersihan dari sudu-sudu turbine sangat berpengaruh terhadap putaran dari turbocharge serta juga berpengaruh terhadap kapasitas udara yang dihasilkan dari putaran itu, sehingga kondisi kebersihan sudu-sudu dari turbocharge harus diperhatikan untuk memperoleh nilai kerja yang maksimal. Gambar sudusudu turbin dapat dilihat pada lampiran

3) Bocornya exhaust gas below (A5)

Peristiwa yang telah dialami
juga merupakan sumber
referensi dari suatu sebab
kurang maksimalnya kinerja
dari turbocharge, terjadi
penurunan kecepatan dari
turbocharge yang diakibatkan
oleh bocornya exhaust gas
below, posisi komponen
tersebut sangat berpengaruh
pada kinerja dari turbocharge
karena terletak pada katup by
pass exhaust gas yang berada di
persimpangan antara arah
langsung menuju cerobong dan
arah menuju susu-sudu pada
turbocharge.

Analisa penyebab top event yang kedua adalah adanya masalah tentang komposisi bahan bakar yang kurang sesuai. Berikut ini adalah penjabaran intermediet event dan basic event untuk permasalahan tersebut. 


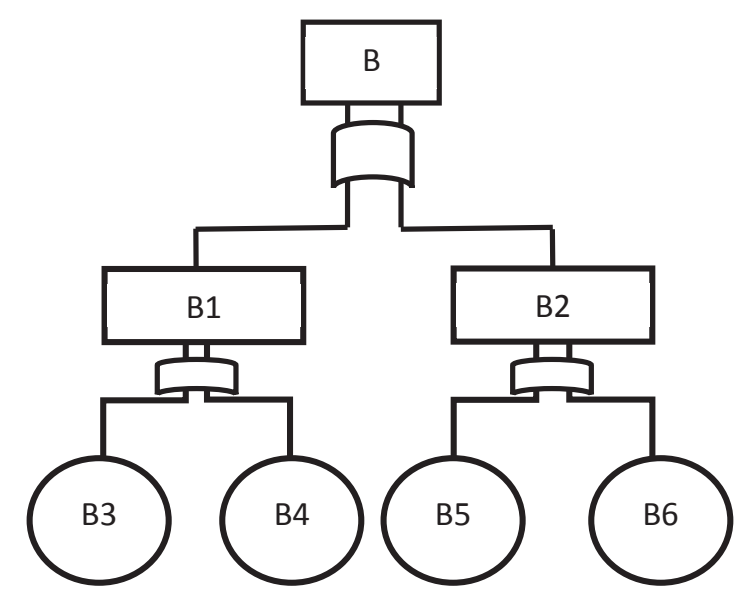

Bagan 3. Pohon kesalahan komposisi bahan bakar untuk pembakaran kurang sesuai

Keterangan:

B : Komposisi bahan bakar untuk pembakaran kurang sesuai

B1 : Terlalu banyak kandungan bahan bakar minyak dalam pembakaran

B2 : Kurangnya suplai bahan bakar gas methane

B3 : Kerusakan fuel injector valve

B4 : Pengaturan rek bahan bakar yang kurang sesuai

B5 : Penurunan tekanan gas masuk

B6 : Kerusakan pada admision gas valve

Penjabaran dari top event kedua komposisi bahan bakar untuk pembakaran yang kurang sesuai, akan dijabarkan dalam beberapa faktor yang mempengaruhi kejadian tersebut, faktor-faktor penyebabnya adalah sebagai berikut:

- Terlalu banyak kandungan bahan bakar minyak dalam pembakaran (B1). Komposisi pembakaran yang sesuai antara udara, bahan bakar minyak, dan gas merupakan syarat mutlak untuk mendapatkan nilai pembakaran yang sempurna di dalam silinder, karena kualitas pembakaran juga berpengaruh terhadap nilai kerja yang dihasilkan pada permesinan tersebut.

Dari bagan di atas dapat dijabarkan bahwa faktor penyebab terlalu banyak kandungan bahan bakar minyak dalam pembakaran adalah:

1. Kerusakan fuel injector valve (B3)

Pengaruh yang diakibatkan jika tidak berfungsinya fuel injector valve secara maksimal adalah komposisi bahan bakar minyak sebagai media pembakaran dalam ruang silinder yang terlalu banyak, jika kuantitas bahan bakar minyak dalam ruang pembakaran terlalu banyak maka akan mengakibatkan salah satunya yaitu suhu gas buang pada dual fuel diesel engine terlalu tinggi.

2. Pengaturan rek bahan bakar yang kurang sesuai

Pengaturan rek bahan bakar pada fuel injection pump juga mempengaruhi kuantitas bahan bakar yang masuk sebagai media pembakaran dalam silinder.

Dari data di atas dapat dijabarkan menggunakan aljabar boolean menggunakan gerbang logika $O R$, karena dari masingmasing basic event tidak saling mempengaruhi dan tidak saling terjadi. Apabila hanya salah satu dari basic event yang terjadi maka kejadian intermediet event akan terjadi. 
- Kurangnya suplai bahan bakar gas methane (B2)

Pada proses yang normal sistem ini berjalan dengan menjaga tekanan bahan bakar methane pada 420 - $550 \mathrm{kPa}$, dan suhu pada $35^{0}-40^{\circ} \mathrm{C}$. Dikarenakan penggunaan G.C.U pada waktu yang bersamaan, ataupun terjadinya kebocoran pada pipa-pipa penyuplai bahan bakar methane menuju kamar mesin.

1. Penurunan tekanan gas yang masuk (B5)

Hal ini disebabkan terpecahnya penyuplaian bahan bakar methane untuk generator induk dan G.C.U. Masalah ini ditemukan pada indicator yang ditunjukan pada ruang G.V.U. Normalnya suhu untuk bahan bakar methane minimal $35^{\circ} \mathrm{C}$ dan tekanan minimal $420 \mathrm{kPa}$. Pada gambar yang dapat dilihat di lampiran menunjukkan bahwa masalah penurunan tekanan bahan bakar methane yang berkisar pada $370 \mathrm{kPa}$.

2. Kerusakan pada gas admission valve (B6)

Terkikisnya permukaan pada lower plate disebabkan adanya gesekan. Dimana pegas atau springs pada bagian moving plate ini mengalami kekendoran sehingga dari proses penutupan dan pembukaan dari moving plate tidak merata. Saat proses katup terbuka, solenoid ini bekerja mengatur dan menekan pegas agar gas masuk dalam silinder.
Keadaan pada moving plate patah di bagian luar antara landasan pegas. Bagian yang hilang atau patah ini memiliki panjang sekitar $27 \mathrm{~mm}$. Faktor penyebab dari patahnya bagian luar dari perimeter disebabkan karena bahan mengalami penurunan kekerasan sehingga terjadinya patah. Penurunan kekerasan ini didukung juga oleh terkikisnya bagian yang patah sehingga menambah beban kekerasan pada bahan ini.

Analisa top event ketiga suhu engine room terlalu panas, maka di bawah ini akan dijabarkan tentang faktor penyebab dari permasalahan tersebut.

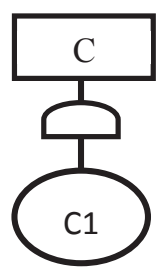

Bagan 4. Pohon kesalahan suhu engine room terlalu panas

Dari bagan di atas dapat dijabarkan bahwa ada faktor tunggal penyebab tingginya suhu engine room terlalu panas $(\mathrm{C})$ yaitu iklim dimana kapal berada (C1).

Daerah operasi kapal LNG/C Tangguh Palung lebih banyak pada daerah tropis atau disekitar garis khatulistiwa maka suhu pada udara di luar kapal sudah tinggi dan jika masuk sebagai udara pembakaran maka juga mempengaruhi tingginya suhu bahan bakar. Temperatur udara 
pada daerah tropis mencapai $35^{\circ} \mathrm{C}$ dibandingkan dengan suhu udara pada daerah iklim sedang dan dingin temperatur udara luar di bawah $20^{\circ} \mathrm{C}$ hal ini sangat berpengaruh pada kualitas udara yang masuk yang digunakan sebagai komposisi pembakaran di dalam ruang silinder.

Maka dapat disimpulkan bahwa faktor tunggal penyebab intermediet event terlalu tingginya suhu engine room $(\mathrm{C})$ adalah iklim dimana kapal berada (C1).

\section{Hasil penelitian}

1. Faktor penyebab tingginya suhu gas buang Dual Fuel Diesel Engine Dari tiap top event $\mathrm{A}, \mathrm{B}$, dan $\mathrm{C}$ sudah dijabarkan dengan FTA. Berikut ini tabel kebenaran dari permasalahan utama.

Tabel 3. Tabel kebenaran faktor penyebab tingginya suhu gas buang Dual Fuel Diesel Engine

\begin{tabular}{|c|c|c|c|}
\hline $\begin{array}{c}\text { Kurangnya } \\
\text { suplai udara } \\
\text { pembakaran } \\
\text { dalam } \\
\text { ruang } \\
\text { silinder }\end{array}$ & $\begin{array}{c}\text { Komposisi } \\
\text { bahan bakar } \\
\text { untuk } \\
\text { pembakaran } \\
\text { yang } \\
\text { kurang } \\
\text { sesuai }\end{array}$ & $\begin{array}{c}\text { Suhu } \\
\text { Engine } \\
\text { Room } \\
\text { terlalu } \\
\text { panas }\end{array}$ & $\begin{array}{c}\text { Tingginya } \\
\text { suhu gas } \\
\text { buang pada } \\
\text { Dual Fuel } \\
\text { Diesel } \\
\text { Engine. }\end{array}$ \\
\hline 0 & 0 & 0 & 0 \\
\hline 0 & 0 & 1 & 1 \\
\hline 0 & 1 & 0 & 1 \\
\hline 1 & 0 & 0 & 1 \\
\hline 1 & 1 & 0 & 1 \\
\hline 1 & 0 & 1 & 1 \\
\hline 0 & 1 & 1 & 1 \\
\hline 1 & 1 & 1 & 1 \\
\hline
\end{tabular}

Jadi dapat ditarik kesimpulan dari top event yang pertama komposisi bahan bakar untuk pembakaran yang tidak sesuai dengan persamaan bolean adalah sebagai berikut:

$\mathrm{X}=\mathrm{A}+\mathrm{B}+\mathrm{C}$

$\mathrm{A}=\mathrm{A} 1+\mathrm{A} 2($ karena $\mathrm{A} 1=\mathrm{A} 3, \mathrm{~A} 2=\mathrm{A} 4+$ $\mathrm{A} 5+\mathrm{A} 6)=\mathrm{A} 3+\mathrm{A} 4+\mathrm{A} 5+\mathrm{A} 6$
$\mathrm{B}=\mathrm{B} 1+\mathrm{B} 2($ karena $\mathrm{B} 1=\mathrm{B} 3+\mathrm{B} 4, \mathrm{~B} 2=$ $\mathrm{B} 5+\mathrm{B} 6)=\mathrm{B} 3+\mathrm{B} 4+\mathrm{B} 5+\mathrm{B} 6$

$\mathrm{C}=\mathrm{C} 1$

Maka cut set dari fault tree analisys dari penyebab tingginya suhu gas buang pada dual fuel diesel engine adalah (A3), (A4), (A5), (B3), (B4), (B5), (B6), (C1), maka hasil analisa kualitatif dari top event tingginya suhu gas buang pada dual fuel diesel engine. Mendapatkan basic event yang mempengaruhi (top event) sebagai berikut:

A3 : Rusaknya Elektro motor

A4 : Tidak sesuainya pembukaan Exhaust Gas Waste Gate Valve

A5 : Kotornya sudu-sudu turbine side pada Turbocharge

A6 : Bocornya exhaust gas below

B3 : Kerusakan fuel injector valve

B4 : Pengaturan rek bahan bakar yang kurang sesuai

B5 : Penurunan tekanan gas masuk

B6 : Kerusakan pada Gas admission valve

C1 : iklim dimana kapal berada

2. Dampak yang diakibatan dari tingginya suhu gas buang terhadap kinerja dari Dual Fuel Diesel Engine.

Tingginya suhu gas buang pada Dual Fuel Diesel Engine akan menimbulkan kerusakan terhadap komponen-komponen pada mesin, dengan rusaknya komponenkomponen permesinan tersebut atau tidak lagi berfungsi sebagaimana mestinya maka akan berpengaruh terhadap kinerja dari Dual Fuel Diesel Engine, kerusakan komponenkomponen dari Dual Fuel Diesel Engine adalah sebagai berikut:

a. Pecahnya below pada exhaust manifold by-pass

Tingginya gas buang yang mencapai suhu $600^{\circ} \mathrm{C}$ saat Dual Fuel Diesel Engine menggunakan gas sebagai bahan bakar utama (Gas Mode) maka akan 
mengakibatkan kerusakan pada komponen-komponen permesinan, salah satunya yaitu komponen below pada exhaust manifol bypass, salah satu faktor penyebab dari rusaknya komponen tersebut yaitu tingginya suhu gas buang, gambar dapat dilihat pada lampiran.

b. Terkikisnya exhaust cilinder head pada Dual Fuel Engine

Karena suhu pada gas buang yang terlalu tinggi juga berpengaruh terhadap kondisi dari cylinder head terutama yang berhubungan terhadap jalur keluaran dari suhu gas buang, sehingga mengakibatkan terkikisnya permukaan pada exhaust cilinder head tersebut, berikut ini diperlihatkan gambar kerusakan dari exhaust cylinder head.

c. Terkikisnya permukaan dari exhaust valve Dual Fuel Diesel Engine

Searah dengan jalur keluaran dari gas buang, maka kondisi dari exhaust valve juga sangat dipengaruhi oleh suhu gas buang tersebut, di dalam permasalahan ini suhu gas buang yang tinggi akan mengakibatkan kondisi fisik dari exhaust valve tersebut juga terpengaruh, khususnya pengaruh terhadap kondisi permukaan dari exhaust valve tersebut yang mengalami pengikisan, berikut ini akan diperlihatkan keadaan dari exhaust valve yang telah dipengaruhi oleh suhu gas buang yang terlalu tinggi.

3. Bagaimana cara mengatasi penurunan kinerja Dual Fuel Diesel Engine

Untuk mengatasi penurunan kinerja dari Dual Fuel Diesel Engine yang diakibatkan oleh tingginya suhu gas buang adalah dengan melakukan tindakan sebagai berikut:

a. Perawatan berencana sesuai dengan sistem perawatan terencana (Planned Maintenance System)

Planned maintenane system terdiri dari banyak elemen seperti perencanaan, pelaksanaan kerja, pencataan dan evaluasi. Tujuan dari sistem ini adalah menyusun rencana dan operasional kerja di atas kapal yang sudah ditetapkan oleh perusahaan yang bertanggung jawab atas manajemen operasional dan berdasarkan ISM (International Safety Management).

b. Melakukan perawatan berencana sesuai dengan buku petunjuk operasional

Langkah-langkah perawatan berencana sesuai dengan buku petunjuk operasional generator induk dan fuel gas system:

1) Perawatan yang dilakukan setiap pelayaran;

2) Perawatan pada saat docking;

3) Melakukan Perawatan Insidentil

a) Penggantian bagian-bagian Gas Admission Valve ataupun penggantian Gas Admission Valve secara menyeluruh

Pada dasarnya proses kerja dari G.A.V adalah berdasarkan dari aktuator yang menerima electric signal dari cylinder control module yang kemudian dari aktuator akan membuka ataupun menutup sesuai dengan kontrol system yang telah diintegrasikan pada G.A.V itu sendiri. Pada saat terjadinya keterlambatan penerimaan respon dari controller dan terjadinya keterlambatan pembukaan dari G.A.V itu sendiri yang dapat disebabkan 
kondisi bagian-bagian G.A.V yang sudah tidak bekerja secara maksimal, sehingga dilakukan penggantian beberapa bagian di dalam G.A.V termasuk O-ring yang sangat penting dalam hal menjaga kevakuman. Namun pada saat terjadinya kerusakan pada filter, penggantian secara menyeluruh harus dilakukan Hal ini dikarenakan, filter pada G.A.V telah diintegrasi dan tidak dapat dilepas.

b) Perawatan dan perbaikan terhadap komponen turbocharge

Agar mencapai nilai kerja yang maksimal hendaknya dilakukan perawatan dan perbaikan secara berkala jika ditemukan kerusakan maupun penurunan nilai kerja dari turbocharge tersebut, perawatan yaitu dengan melakukan flashing pada sudusudu turbin saat mesin beroperasi, dengan melakukan flashing agar kiranya dapat mengurangi volume jelaga yang menempel pada sudu-sudu tersebut.

c) Perbaikan dan perawatan terhadap waste gate valve exhaust gas

Waste gate valve merupakan komponen vital yang mempengaruhi kinerja dari turbocharge, jika terjadi kerusakan maupun kesalahan kalibrasi terhadap komponen tersebut harus segera dilakukan inspeksi dan jika diperlukan harus dilakukan penanganan secepatnya.

\section{PENUTUP}

Berdasarkan pembahasan pada bab-bab sebelumnya, tentang analisa penyebab tingginya suhu gas buang terhadap kinerja Dual Fuel Diesel Engine dengan menggunakan metode fault tree analysis. Sebagai bagian akhir dari penelitian ini penulis memberikan kesimpulan dan saran yang berkaitan dengan masalah yang dibahas dalam penelitian ini, yaitu:

\section{A. Kesimpulan}

Kesimpulan yang dapat diambil dari penelitian tentang analisa penyebab tingginya suhu gas buang terhadap kinerja Dual Fuel Diesel Engine di MV. Tangguh Palung dengan menggunakan metode fault tree analysis adalah:

1. Dengan menggunakan metode fault tree analysis maka diperoleh intermediet event faktor-faktor penyebab tingginya suhu gas buang yaitu kurangnya suplai udara pembakaran dalam ruang silinder yang seharusnya mencapai $17 \mathrm{~kg} / \mathrm{s}$ tetapi udara yang masuk hanya 13 $\mathrm{kg} / \mathrm{s}$, komposisi bahan bakar untuk pembakaran yang kurang sesuai diindikasikan dengan penurunan tekanan bahan bakar gas yang masuk berkisar pada $370 \mathrm{kPa}$ sedangkan tekanan normal harus mencapai 420 $\mathrm{kPa}$ dan suhu Engine Room yang terlalu panas mencapai $35^{\circ} \mathrm{C}$, serta dari masing-masing intermediet event akan diperoleh basic event yang tidak dapat dicari lagi penyebabnya.

2. Dampak yang diakibatkan terlalu tingginya suhu gas buang pada Dual Fuel Diesel Engine adalah pecahnya below pada exhaust manifold by-pass, terkikisnya exhaust cilinder head pada permukaan tepinya, serta terkikisnya permukaan dari exhaust valve dual fuel diesel engine. sehingga dapat mempengaruhi masa kerja dari komponen-komponen tersebut, apabila komponenkomponen tersebut mengalami kerusakan maka kinerja dari Dual Fuel Diesel Engine tidak mencapai nilai kerja yang maksimal. 
3. Setelah diketahui faktor-faktor yang mempengaruhi tingginya suhu gas buang pada Dual Fuel Diesel Engine, maka cara yang dilakukan untuk mengatasinya adalah dengan melakukan perawatan berencana sesuai dengan manual instruction book dan melakukan perawatan insidentil yaitu perawatan dan perbaikan terhadap komponen turbocharge, perawatan dan perbaikan terhadap Gas Admission Valve secara menyeluruh maupun hanya pada bagian yang mengalami masalah, perawatan dan perbaikan pada waste gate exhaust gas, serta pengoperasian engine room blower pada high speed mode.

\section{B. Saran}

Dari permasalahan yang sudah diuraikan dan diberikan solusi untuk pemecahannya, agar tingginya suhu gas buang tidak mempengaruhi kinerja dari Dual Fuel Diesel Engine. Untuk itu, penulis paparkan saran-sarannya sebagai berikut:

1. Sebaiknya dalam melakukan perawatan berkala khususnya terhadap komponen atau sistem pendukung yang berhubungan dengan sistem gas buang pada Dual Fuel Diesel Engine, harus sesuai dengan Manual Instruction Book agar pada mesin tersebut mencapai nilai kerja yang maksimal.

2. Seyogyanya dilakukan sesegera mungkin perbaikan dan penggantian spare part terhadap komponen permesinan yang mengalami kerusakan akibat dari tingginya suhu gas buang pada Dual Fuel Diesel Engine agar tidak menyebabkan dampak yang lebih fatal dalam kerusakan komponen-komponen permesinan.

3. Sebaiknya dalam melakukan perawatan dan pemeliharaan terhadap sistem gas buang pada Dual Fuel Diesel Engine harus dilaksanakan secara sistematis dan menyeluruh. karena itu merupakan satu kesatuan kerja dan adanya saling ketergantungan antara bagian yang satu dengan bagian yang lainnya.

\section{DAFTAR PUSTAKA}

Wiley, Jhon and Sons. Fathoni, Abdurrahmat. 2006. Metodelogi Penelitian dan Teknik Penyusunan Skripsi. Jakarta: PT. Asdi Mahasatya

Kristiansen, Svein. 2005. Maritime Transportation Safety Management Risk Anaysis. London: Great Britain

Kuo, Chengi. 2007. Safety Management and its Maritime Aplication. England: Modern Colour Solution

Samsung Heavy Industry. Cargo Operating Manual

Samsung Heavy Industry. Machinery Operating Manual

Sujarweni, V. Wiratna. 2014. Metodologi Penelitian. Yogyakarta : Pustaka Baru Press

Wartsila. 50DF Engine Manual, Instruction and Equipment. Finlandia 